\title{
Effects of Olanzapine on Regional C-Fos Expression in Rat Forebrain
}

\author{
George S. Robertson, Ph.D, and H. Christian Fibiger, Ph.D
}

Compared to typical antipsychotic drugs, clozapine produces a unique pattern of Fos-like immunoreactive neurons in the rat forebrain. It has been proposed, therefore, that this approach may be useful in identifying other agents with clozapine's therapeutic profile. In the present study, we examined the ability of olanzapine to increase the number of Fos-like immunoreactive neurons in the striatum, nucleus accumbens, lateral septal nucleus, and prefrontal cortex. Olanzapine $(5,10 \mathrm{mg} / \mathrm{kg})$ produced dose-dependent increases in the number of Fos-positive neurons in the nucleus accumbens and lateral septal nucleus, important components of the limbic system that may mediate some of the therapeutic actions of neuroleptics. Olanzapine also produced dose-dependent increases in the number of Fospositive neurons in the dorsolateral striatum, an effect that correlates with the ability of neuroleptics to produce extrapyramidal side-effects. The effects of olanzapine on regional c-fos expression are not therefore identical to clozapine, which is without effect in the dorsolateral striatum. However, olanzapine-induced increases in the dorsolateral striatum were considerably smaller than those generated in the nucleus accumbens suggesting that at low, potentially therapeutic doses olanzapine may not generate significant extrapyramidal side effects. Olanzapine also increased the number of Fos-positive neurons in medical prefrontal cortex, an action unique to clozapine and a few other atypical antipsychotics. These findings are consistent with the hypothesis that olanzapine is an atypical antipsychotic in the sense that it does not produce significant extrapyramidal side-effects at low therapeutic doses. However, extrapyramidal side-effects at higher doses can be predicted by these results. Finally, olanzapine's actions in the medial prefrontal cortex may be predictive of a clozapine-like profile with respect to actions on negative symptoms in schizophrenia. Additional clinical experience with olanzapine and other new antipsychotics is required to test the validity of these hypotheses. [Neuropsychopharmacology 14:105-110, 1996]
KEY WORDS: Schizophrenia; Olanzapine; Atypical antipsychotics; Immediate-early genes; $c$-fos; Extrapyramidal side-effects

Whereas neuroleptics are clearly useful in the treatment of schizophrenia, most of these compounds produce extrapyramidal side-effects (EPS) and have limited actions on negative symptoms (Baldessarini 1990; Borison et al.

From the Department of Pharmacology (GSR), Faculty of Medicine, University of Ottawa, Ottawa, Ontario, Canada; Division of Neurological Sciences (HCF), Department of Psychiatry, University of British Columbia, Vancouver, British Columbia, Canada.

Address correspondence to Hans C. Fibiger, Department of Psychiatry, University of British Columbia, 2255 Wesbrook Mall, Vancouver, British Columbia V6T 1Z3, Canada.

Received June 28, 1995; revised August 10, 1995; accepted September 28, 1995.
1983; Deutch et al. 1991). By comparison, clozapine is considered atypical because it does not produce EPS and can target both positive and negative symptoms of schizophrenia (for review see Baldessarini and Frankenburg, [1991]). Moreover, clozapine has been shown to be a more effective antipsychotic than chlorpromazine or haloperidol in two multicenter clinical trials (Claghorn et al. 1987; Kane et al. 1988). Unfortunately, approximately $1 \%$ of patients treated with clozapine develop agranulocytosis (Idanpaan-Heikkela et al. 1977). This potentially lethal side-effect has resulted in the search for other compounds that share clozapine's desirable therapeutic profile.

The thienobenzodiazepine, olanzapine, is a novel, potentially atypical antipsychotic that has a receptorbinding profile similar to clozapine. Thus, both olanza- 
pine and clozapine display high affinities for dopamine $\mathrm{D}_{1}, \mathrm{D}_{2}$, and $\mathrm{D}_{4}$, serotonin $5-\mathrm{HT}_{2} \mathrm{~A}, 5-\mathrm{HT}_{3}$, and $5-\mathrm{HT}_{6}$, $\alpha_{1}$-adrenergic, histamine ${ }_{1}$, and muscarinic receptors (Bymaster et al. 1996). The effects of olanzapine and clozapine in behavioral tests such as 5-HTP-induced head twitches, conditioned avoidance responding, apomorphine-induced climbing, punished responding, and drug discrimination studies are also comparable (Moore et al. 1992). Furthermore, like clozapine, chronic olanzapine administration decreases the number of spontaneously active A10, but not A9, dopamine neurons (Stockton and Rasmussen 1996). These findings raise the possibility that olanzapine may also share clozapine's desirable clinical features. In support of this hypothesis, olanzapine has recently been reported to reduce both the negative and positive symptoms of schizophrenia at doses that produce few, if any, signs of EPS (Beasley et al. 1996).

Neuronal synthesis of the putative activity marker Fos is potently elevated in the dorsolateral striatum by typical, but not atypical, antipsychotics (Dragunow et al. 1990; Deutch et al. 1992; Nguyen et al. 1992; Robertson et al. 1994). Because the dorsolateral striatum plays an important role in the regulation of movement (Pisa 1988; Carelli and West 1991), this finding has led to the proposal that the EPS potential of antipsychotics can be predicted on the basis of their ability to elevate c-fos mRNA or Fos-like immunoreactivity (FLI) in the dorsolateral striatum (Merchant and Dorsa 1993; Robertson et al. 1994). In contrast, both typical and atypical antipsychotics increase FLI in the nucleus accumbens, this being the only structure in which c-fos expression is enhanced by all antipsychotic agents tested to date and thus suggesting that antipsychotic activity is predicted most consistently by actions in this nucleus (Robertson et al. 1994). Clozapine and a few other atypical antipsychotics also increase FLI in medial portions of the prefrontal cortex (Robertson et al. 1994). As metabolic hypofrontality in schizophrenia has been reported to correlate with the presence of negative symptoms (Weinberger 1988), Robertson and Fibiger (1992) have suggested that clozapine's actions on negative symptoms may be correlated with its effects on c-fos expression in this structure.

The fact that different neuroleptics produce distinctive patterns of increased FLI indicates that this approach may be useful in identifying new antipsychotic agents with desirable clinical profiles. Given that olanzapine has much in common with clozapine's receptor binding profile, the present study examined olanzapine's effects on regional c-fos expression in the forebrain.

\section{METHODS}

\section{Drug Treatment}

Three groups of male Wistar rats ( 300 to $350 \mathrm{~g}$ ), each composed of four animals, were injected subcutane- ously (sc) with one of the following: vehicle $(1 \mathrm{ml} / \mathrm{kg}$; $40 \mu \mathrm{l}$ of $20 \%$ acetic acid in $1 \mathrm{ml}$ of distilled water) or olanzapine ( 5 or $10 \mathrm{mg} / \mathrm{kg}$; dissolved in $1 \mathrm{ml}$ of vehicle). Two hours after the injection, all of the animals were deeply anesthetized with pentobarbital $(100 \mathrm{mg} / \mathrm{kg}$ IP) and perfused with saline $(200 \mathrm{ml})$ followed by 200 $\mathrm{ml}$ of $4 \%$ paraformaldehyde in phosphate buffered $(0.1$ mol/l) saline. Each brain was removed immediately after perfusion and placed in fresh fixative for at least 12 hours.

\section{Immunohistochemistry}

After the postfixation period, $30 \mu \mathrm{mol} / \mathrm{L}$ sections were cut from each brain using a vibratome. Fos-like immunoreactivity was detected using a sheep polyclonal antibody (Cambridge Research Biochemicals, CRB OA-11823) directed against residues 2 to 16 of the $\mathrm{N}$-terminal region of the Fos molecule. Sections were washed three times with $0.02 \mathrm{~mol} / \mathrm{L}$ phosphate buffered saline (PBS) and then incubated in PBS containing 0.3\% hydrogen peroxide for 10 minutes to block endogenous peroxidase activity. Sections were then washed three times in PBS and incubated in PBS containing 0.3\% Triton X-100, $0.02 \%$ azide, and Fos primary antisera (diluted 1:2000) for 48 hours. The sections were washed three times with PBS and incubated with a biotinylated rabbit antisheep secondary antibody (Vector Laboratories; diluted 1:200) for 1 hour. The sections were then washed three times with PBS and incubated for 1 hour with PBS containing $0.3 \%$ Triton X-100 and $0.5 \%$ avidin-biotinylated horseradish peroxidase complex (Vector Laboratories). After three washes in PBS the sections were rinsed in 0.1 $\mathrm{mol} / \mathrm{L}$ acetate buffer, $\mathrm{pH}$ 6.0. The reaction was visualized using a glucose oxidase-DAB-nickel method described previously (Shu and Fan 1988). The reaction was terminated by washing in acetate buffer, and the sections were mounted on chrom-alum-coated slides, dehydrated, and prepared for microscopic observation.

\section{Counting Immunoreactive Cells}

The number of FLI-containing neurons in the nucleus accumbens, striatum, prefrontal cortex, and lateral septal nucleus was determined using an image analysis system equipped with Image 1.47 software (Wayne Rasband, NIMH) according to Robertson et al. (1995). Camera lucida drawings illustrating each sampled area $(660 \times$ $800 \mu \mathrm{mol} / \mathrm{L}$ ) of sections used for cell counts in the prefrontal cortex (A), nucleus accumbens (B), medial and dorsolateral striatum (C), and lateral septal nucleus (D) are shown in Figure 1. A total of two measurements, each performed on a different brain section, was conducted for every animal. 

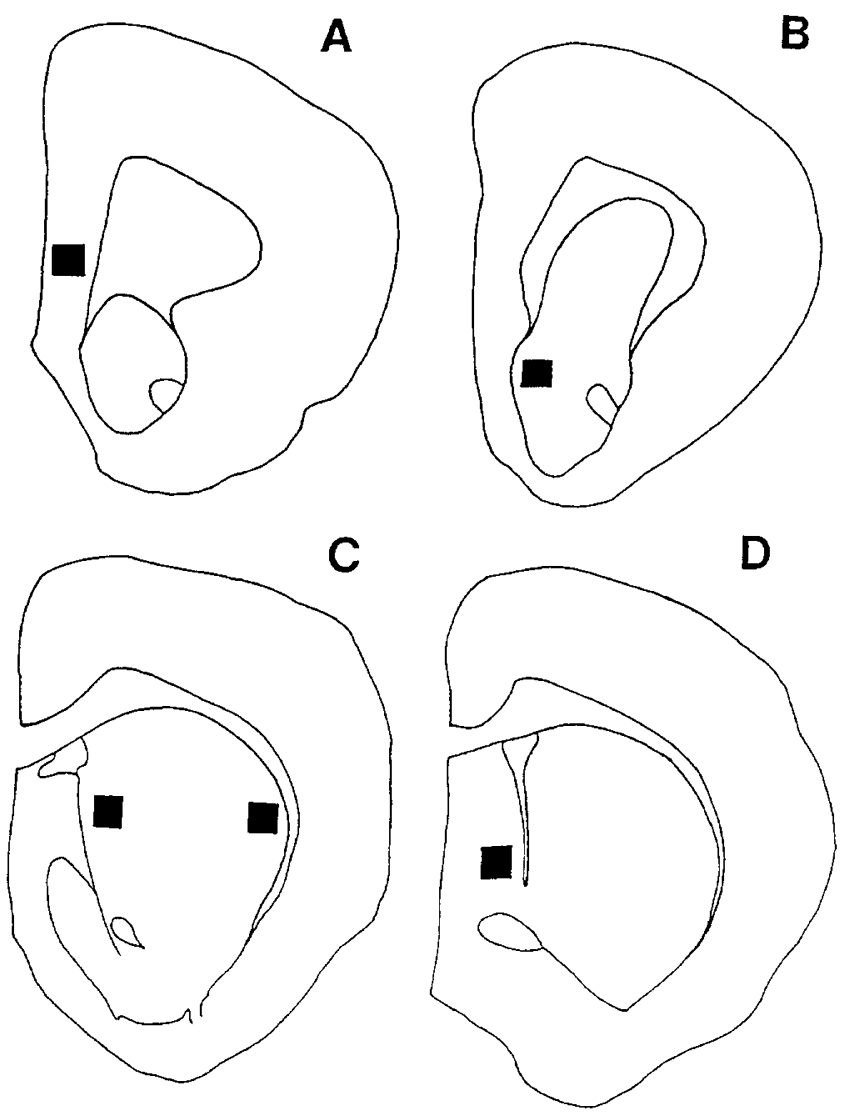

Figure 1. Camera lucida drawings of representative sections used for the counting of Fos-positive neurons in the prefrontal cortex (A), nucleus accumbens (B), medial and dorsolateral striatum (C), and lateral septal nucleus (D).

\section{Data Analysis}

A one-way analysis of variance was performed on the cell count data for each brain region. If the ANOVA was significant, multiple comparisons were performed using the Newman-Keuls test.

\section{RESULTS}

Compared to the vehicle-injected animals, the high dose of olanzapine $(10 \mathrm{mg} / \mathrm{kg})$ produced significant increases in the number of Fos-like positive neurons in all of the brain structures examined (Figures 1 and 2). The lower dose $(5 \mathrm{mg} / \mathrm{kg})$ produced significant increases in the nucleus accumbens, dorsolateral striatum, and lateral septal nucleus (Figures 1 and 2). Olanzapine had relatively greater effects in the nucleus accumbens than in the dorsolateral striatum. In order to quantify the magnitude of this difference, the "atypical index" was calculated according to Robertson et al. (1994). In brief, to determine this index it was necessary to correct for those effects produced by the injection procedure itself.
This was done by subtracting the number of Fos-positive neurons in the nucleus accumbens and dorsolateral striatum observed after a vehicle injection from the number produced by each dose of olanzapine. Next, this corrected value for the dorsolateral striatum was subtracted from the corrected accumbal value for each drug dose. This calculation yielded the atypical index, that is, the number of Fos-positive neurons in the nucleus accumbens minus the number in the dorsolateral striatum (Robertson et al. 1994). The atypical index for olanzapine was positive at both the 5 and $10 \mathrm{mg} / \mathrm{kg}$ doses (i.e., +19 and +30 , respectively), indicating that olanzapine met this criterion for an atypical antipsychotic.

\section{DISCUSSION}

Acute administration of olanzapine elevated the number of Fos-like positive neurons in the nucleus accumbens in a dose-dependent manner. At present, the nucleus accumbens is the only brain region in which all known antipsychotics increase c-fos expression (Merchant and Dorsa 1993; Robertson et al. 1994), and this has led to the suggestion that the nucleus accumbens may be an important site of antipsychotic activity (Deutch et al. 1992; Robertson et al. 1994). The ability of olanzapine, which appears to be a clinically effective antipsychotic, to elevate FLI in the nucleus accumbens is consistent with this hypothesis.

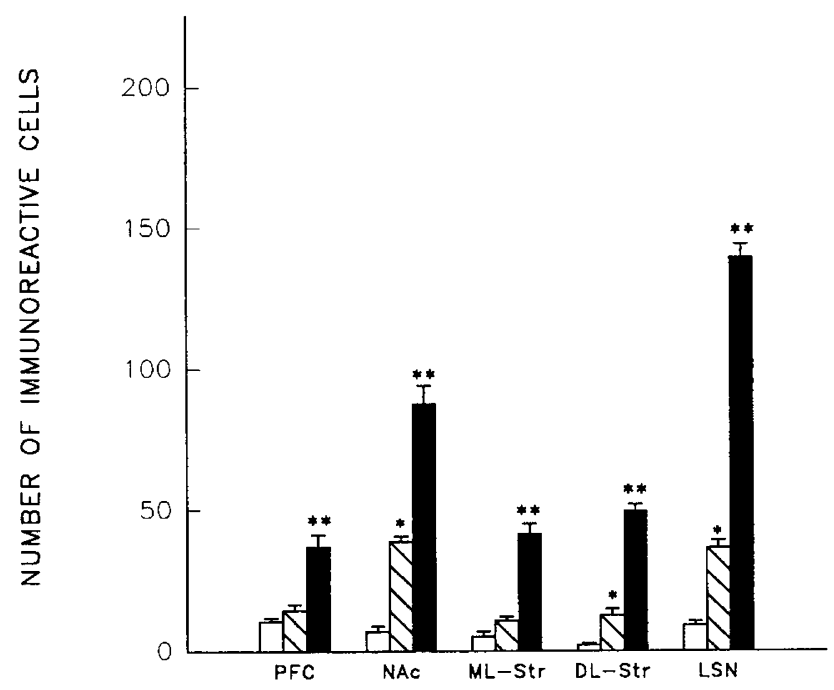

Figure 2. Effects of clozapine on the average number of Foslike immunoreactive neurons detected within a $660 \times 800$ $\mu \mathrm{m}$ area of the medial prefrontal cortex (PFC), nucleus accumbens (NAc), medial striatum (ML-Str), dorsolateral striatum (DL-Str) and lateral septal nucleus (LSN). Each bar represents the mean \pm SEM of data from four animals. * Significantly different from vehicle control $(p<.01)$. **Significantly different from vehicle control and olanzapine $(5 \mathrm{mg} / \mathrm{kg})(p<.01)$. 
Olanzapine also produced a dose-dependent increase in the number of Fos-positive neurons in the dorsolateral striatum. Because the dorsolateral striatum is involved in the regulation of movement (Pisa 1988; Carelli and West 1991), it has been proposed that neuroleptic-induced increases in c-fos expression in this region are predictive of a propensity to produce EPS (Deutch et al. 1992; Merchant and Dorsa 1993; Nguyen et al. 1992; Robertson and Fibiger 1992). In agreement with this hypothesis, neuroleptics that produce EPS potently increase c-fos mRNA and Fos-like immunoreactivity in the dorsolateral striatum (Merchant and Dorsa 1993; Nguyen et al. 1992; Deutch et al. 1992; Robertson et al. 1994). However, there is not a perfect relationship between the ability of a compound to elevate FLI in the dorsolateral striatum and its liability for producing EPS (Robertson et al. 1994). Several compounds such as thioridazine, melperone, and risperidone that reportedly produce relatively little EPS at therapeutic doses (Baldessarini 1990; Bjerkenstedt 1989; Claus et al. 1992) increase FLI in the dorsolateral striatum. In order to provide a more precise means by which to predict the
EPS potential of these compounds, an atypical index has been developed based on the difference between the number of neurons that display neuroleptic-induced FLI in the nucleus accumbens versus the dorsolateral striatum (Robertson et al. 1994). If a compound produces a larger increase in the number of FLI-positive neurons in the nucleus accumbens than in the dorsolateral striatum, the atypical index is positive, and such a compound is classified as an atypical antipsychotic. Conversely, a compound that produces a smaller enhancement of FLIpositive neurons in the nucleus accumbens than in the dorsolateral striatum generates a negative number and is classified as a typical antipsychotic, that is, one that produces EPS at clinically effective doses. Using this classification procedure in a recent study, 17 antipsychotic compounds were correctly classified according to their clinical EPS profiles (Robertson et al. 1994). According to this classification scheme, olanzapine is an atypical antipsychotic. This is in agreement with recent clinical findings that indicate olanzapine has a low potential for inducing EPS (Beasley et al. 1996). Nevertheless, the ability of olanzapine to dose dependently elevate
Figure 3. Photomicrographs of Fos-like immunoreactive neurons in the nucleus accumbens $(\mathbf{A}, \mathbf{B}, \mathbf{C})$ and dorsolateral striatum (D, E, F) 2 hours after administration of vehicle $(1 \mathrm{ml} / \mathrm{kg})(\mathbf{A}, \mathrm{D})$, olanzapine (5 $\mathrm{mg} / \mathrm{kg})(\mathbf{B}, \mathbf{E})$ or olanzapine $(10 \mathrm{mg} / \mathrm{kg})(\mathbf{C}, \mathbf{F})$. In (B) and $(\mathrm{C})$, arrows indicate the major island of Calleja. Scale bar $=200 \mu \mathrm{m}$.
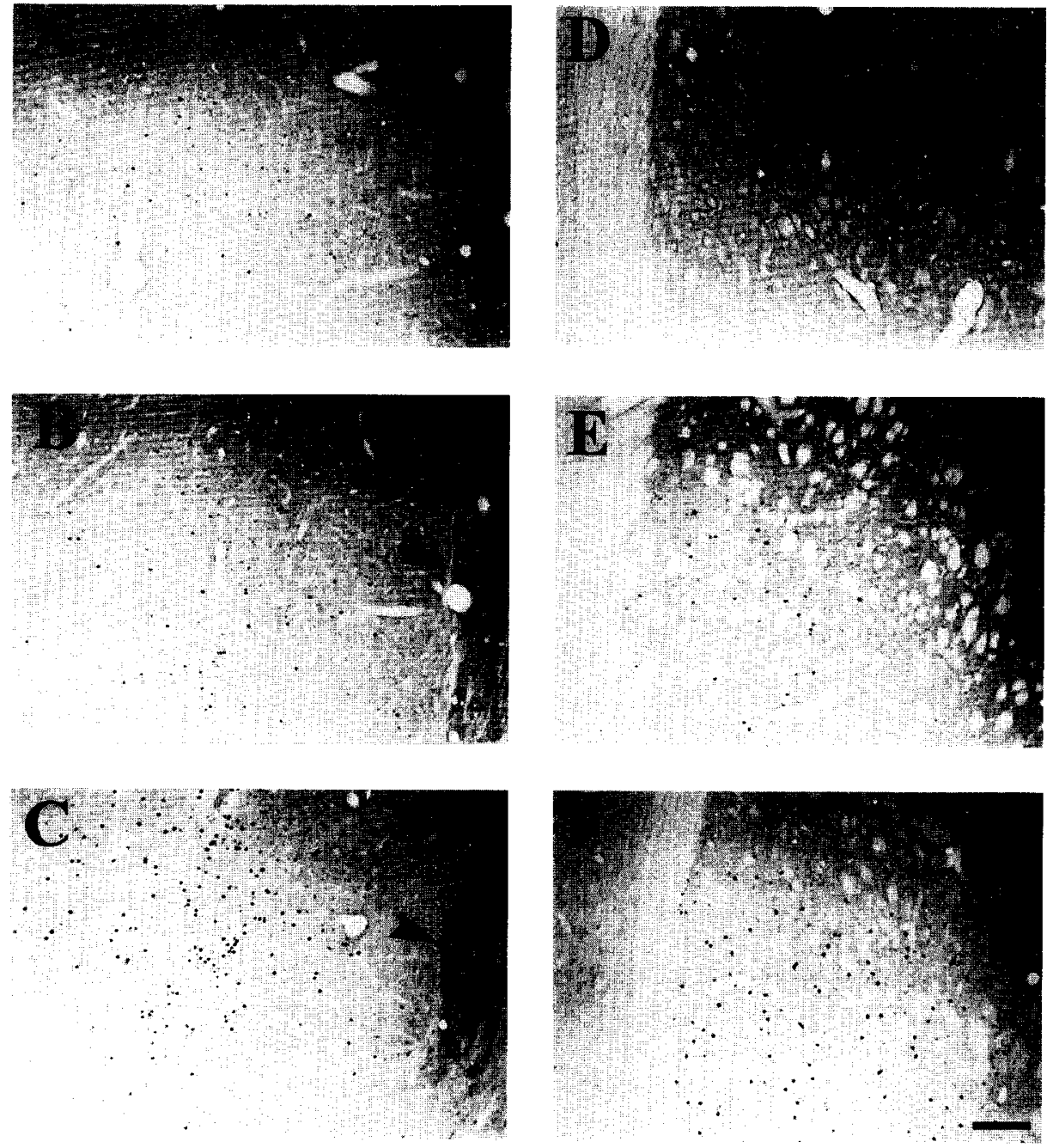
FLI in the dorsolateral striatum suggests that at higher doses this compound may produce EPS. It is noteworthy that olanzapine differs from clozapine in this regard as the latter compound fails to induce c-fos expression in the dorsolateral striatum even at doses up to $30 \mathrm{mg}$ / $\mathrm{kg}$ (Robertson et al. 1994). On the basis of these data, it can be predicted that unlike clozapine and perhaps more like risperidone, olanzapine will produce EPS at higher doses, but that there will exist a dose window at which antipsychotic activity can be produced in the absence of significant EPS. Preliminary clinical data appear to be consistent with this hypothesis (Beasley et al. 1995).

Olanzapine also produced a large increase in the number of FLI-positive neurons in the lateral septal nucleus. Apart from risperidone, all of the antipsychotic drugs examined to date (more than 20 compounds) elevate FLI in the lateral septal nucleus suggesting that this limbic structure may be an important site of antipsychotic activity (Robertson et al. 1994). This nucleus has numerous connections with other limbic structures including the nucleus accumbens, hippocampus, amygdala, and hypothalamus and has been implicated in a variety of motivated and emotional behaviors (Brodal 1981; Krettek and Price 1978; Swanson and Cowan 1979; Thomas 1988). Moreover, with regard to schizophrenia, it is of considerable interest that electrophysiologic abnormalities in this part of the brain correlate most consistently with acute psychotic episodes (Heath 1975; 1977).

Like clozapine, olanzapine apparently targets both positive and negative symptoms of schizophrenia (Beasley et al. 1995; Kane et al. 1988; Meltzer et al. 1989). In vivo imaging studies suggest that a reduction in neuronal activity in the prefrontal cortex may contribute to the pathophysiology of schizophrenia (Berman et al. 1986; Franzen and Ingvar 1974). In particular, Weinberger (1988) has proposed that hypofrontality is associated with negative symptoms. If this hypothesis is correct, then clozapine and olanzapine may improve negative symptoms by enhancing activity in the prefrontal cortex. It should be noted, however, that in the case of olanzapine, increased c-fos expression in the PFC was only seen at the higher dose. In view of the fact that this dose also had obvious effects in the striatum (Figure 2), this raises the possibility that any actions of olanzapine in ameliorating negative symptoms may only be realized at doses that also produce EPS.

Radioligand binding studies indicate that olanzapine has significant affinity for $D_{1}, D_{2}$, and $D_{4}$ dopamine receptors (Bymaster et al. 1995). Neuroleptics are thought to elevate FLI in the dorsolateral striatum by their antagonist actions at $\mathrm{D}_{2}$ dopamine receptors (Deutch et al. 1992; Guo et al. 1995; Nguyen et al. 1992; Robertson and Fibiger 1992). It seems likely that olanzapineinduced FLI in the dorsolateral striatum is also mediated by $D_{2}$ receptor blockade. In contrast, recent evidence suggests that clozapine may, at least in part, increase FLI in the nucleus accumbens, lateral septal nucleus, and major island of Calleja by blocking $D_{3}$ receptors (Guo et al. 1995). The fact that the major island of Calleja contains $D_{3}$, but not $D_{2}$, dopamine receptor mRNA further suggests that clozapine induces FLI in this region by blocking $D_{3}$ receptors (Bouthenet et al. 1991). At present, olanzapine's affinity for $D_{3}$ receptors has not been reported. However, the ability of olanzapine to elevate FLI in the major island of Calleja raises the possibility that in vivo this compound has, like clozapine, some affinity for $\mathrm{D}_{3}$ dopamine receptors. The extent to which actions at these receptors contribute to the therapeutic actions of these compounds remains to be determined.

\section{ACKNOWLEDGMENTS}

This work was supported by grants from the Medical Research Council of Canada (GSR and HCF).

\section{REFERENCES}

Baldessarini RJ (1990): Drugs and the treatment of psychiatric disorders. In Goodman AG, Ral TW, Nies AS, Taylor $P$ (eds), Goodman and Gilman's The Pharmacological Basis of Therapeutics, 8th ed. New York, Pergamon Press, pp 383-435

Baldessarini RJ, Frankenburg FR (1991): Clozapine: A novel antipsychotic. New Engl J Med 324:746-754

Beasley CM, Tollefson GD, Tran P, Satterlee W, Sanger T, Holman S, HGAD Olanzapine Study Group (1996): Olanzapine versus placebo and haloperidol: Acute phase results of the North American double-blind olanzapine trial. Neuropsychopharmacology 14:111-123

Berman KF, Zec RF, Weinberger DR (1986): Physiological dysfunction of the dorsolateral prefrontal cortex in schizophrenia. Arch Gen Psychiatry 43:126-135

Bjerkenstedt L (1989): Melperone in the treatment of schizophrenia. Acta Psychiatr Scand Suppl 352:35-39

Borison RL, Hitri A, Blowers AJ, Diamond B (1983): Antipsychotic drug action: Clinical, biochemical, and pharmacological evidence for site specificity of action. Clinical Neuropharmacol 6:137-150

Bouthenet M-L, Souil E, Martres M-P, Sokoloff P, Giros B, Schwartz J-C (1991): Localization of dopamine $\mathrm{D}_{3}$ receptor mRNA in the rat brain using in situ hybridization histochemistry: Comparison with dopamine $\mathrm{D}_{2}$ receptor mRNA. Brain Res 564:203-219

Brodal A (1981): Neurological Anatomy in Relation to Clinical Medicine, 3rd ed. New York, Oxford University Press, pp 663-667

Bymaster FP, Calligaro DO, Falcone JF, Marsh RD, Moore ND, Tye NC, Seeman P, Wong DT (1996): Radioreceptor binding profile of the atypical antipsychotic olanzapine. Neuropsychopharmacology 14:87-96 
Carelli RM, West MO (1991): Representation of the body by single neurons in the dorsolateral striatum of the awake, unrestrained rat. J Comp Neurol 309:231-249

Claghorn J, Honigfeld G, Abuzzahab FS, Steinbook AR, Tuason V, Klerman G (1987): The risks and benefits of clozapine versus chlorpromazine. J Clin Psychopharmacol 7:377-384

Claus A, Bollen J, De Cuyper H, Eneman M, Malfroid M, Peuskens J, Heylen S (1992): Risperidone versus haloperidol in the treatment of chronic schizophrenic inpatients: A multicenter double-blind comparative study. Acta Psychiatr Scand 85:295-305

Deutch AY, Moghaddam B, Innis RB, Krystal JH, Aghajanian GK, Bunney BS, Charney DS (1991): Mechanisms of action of atypical antipsychotic drugs: Implications for novel therapeutic strategies for schizophrenia. Schizophr Res 4:121-156

Deutch AY, Lee MC, Iadarola MJ (1992): Regionally specific effects of atypical antipsychotic drugs on striatal Fos expression: The nucleus accumbens shell as a locus of antipsychotic action. Mol Cell Neurosci 3:332-341

Dragunow M, Robertson GS, Faull RLM, Robertson HA, Jansen $K(1990): D_{2}$ dopamine receptor antagonists induce Fos and related proteins in rat striatal neurons. Neuroscience 37:287-294

Franzen G, Ingvar DH (1974): Absence of activation in frontal structures during psychological testing of chronic schizophrenia. J Neurol Neurosurg Psychiatry 38:10271032

Guo N, Klitenick MA, Tham CS, Fibiger HC (1995): Receptor mechanisms mediating clozapine-induced c-fos expression in the forebrain. Neuroscience 65:747-756

Heath RG (1975): Brain function and behavior. I. Emotional and sensory phenomena in psychotic patients and in experimental animals. J Nerv Ment Dis 160:159-175

Heath RG (1977): Modulation of emotion with a pacemaker: Treatment for intractable psychiatric illness. J Nerv Ment Dis 165:300-317

Idanpaan-Heikkela J, Alhaba J, Olkinuora M, Palva IP (1977): Agranulocytosis during treatment with clozapine. Eur J Clin Pharmacol 11:193-198

Kane J, Honigfeld G, Singer J, Meltzer H (1988): Clozapine for the treatment-resistant schizophrenic. Arch Gen Psychiatry 45:789-796

Krettek JE, Price JL (1978): Amygdaloid projections to sub- cortical structures within the basal forebrain in the rat and cat. J Comp Neurol 178:225-254

Meltzer H, Bastani B, Kwon KY, Ramirez LF, Burnett S, Sharpe J (1989): A prospective study of clozapine in treatment-resistant schizophrenic patients. I. Preliminary report. Psychopharmacology 99:S68-S72

Merchant KM, Dorsa DM (1993): Differential induction of neurotensin and c-fos gene expression by typical and atypical antipsychotics. Proc Natl Acad Sci USA 90: 3447-3451

Moore NA, Tye NC, Axton MS, Risius F (1992): The behavioral pharmacology of olanzapine, a novel "atypical" antipsychotic agent. J Pharmacol Exp Ther 262:545-551

Nguyen TV, Kosofsky BE, Birnbaum R, Cohen BM, Hyman SE (1992): Differential expression of c-fos and Zif 268 in rat striatum after haloperidol, clozapine, and amphetamine. Proc Natl Acad Sci USA 89:4270-4274

Pisa M (1988): Motor functions of the striatum of the rat: Critical role of the lateral region in tongue and forelimb reaching. Neuroscience 24:453-463

Robertson GS, Fibiger HC (1992): Neuroleptics increase c-fos expression in the forebrain: Contrasting effects of haloperidol and clozapine. Neuroscience 46:315-328

Robertson GS, Matsumura H, Fibiger HC (1994): Induction patterns of neuroleptic-induced Fos-like immunoreactivity as predictors of atypical antipsychotic activity. J Pharmacol Exp Ther 271:1058-1066

Robertson GS, Tetzlaff W, Bedard A, St-Jean M, Wigle N (1995): C-fos mediates antipsychotic-induced neurotensin gene expression in the rodent striatum. Neuroscience 67:325-344

Shu S, Fan L (1988): The glucose oxidase-DAB-nickel method in peroxidase histochemistry of the nervous system. Neurosci Lett 85:169-171

Stockton ME, Rasmussen K (1996): Electrophysiological effects of olanzapine, a novel atypical antipsychotic on A9 and A10 dopamine neurons. Neuropsychopharmacology 14:97-104

Swanson LW, Cowan WM (1979): The connections of the septal region of the rat. J Comp Neurol 186:621-656

Thomas E (1988): Forebrain mechanisms in the relief of fear: The role of the lateral septum. Psychobiology 16:36-44

Weinberger DR (1988): Schizophrenia and the frontal lobe. Trends Neurosci 8:367-370 